\title{
Robotic assisted minimally invasive thymectomy with simultaneous bilateral thoracoscopy and contralateral phrenic nerve visualization
}

\author{
Nicholas R. Hess, Nicholas Baker, Ryan M. Levy, Arjun Pennathur, Neil A. Christie, James D. Luketich, \\ Inderpal S. Sarkaria
}

Department of Cardiothoracic Surgery, University of Pittsburgh School of Medicine and University of Pittsburgh Medical Center, Pittsburgh, PA, USA

Contributions: (I) Conception and design: NR Hess, IS Sarkaria; (II) Administrative support: A Pennathur, JD Luketich, IS Sarkaria; (III) Provision of study materials or patients: N Baker, RM Levy, NA Christie, JD Luketich, IS Sarkaria; (IV) Collection and assembly of data: NR Hess; (V) Data analysis and interpretation: NR Hess, IS Sarkaria; (VI) Manuscript writing: All authors; (VII) Final approval of manuscript: All authors.

Correspondence to: Inderpal S. Sarkaria. University of Pittsburgh Medical Center, Department of Cardiothoracic Surgery, Division of Thoracic Surgery, University of Pittsburgh Medical Center, Hillman Cancer Center, 5115 Centre Ave., $2^{\text {nd }}$ Floor, Pittsburgh, PA 15232, USA. Email: sarkariais@upmc.edu.

Background: Thoracoscopic approaches to thymectomy and anterior mediastinal mass resection has become increasingly common due to the potential for decreased blood loss and hospital length of stay. However, contralateral mediastinal and phrenic nerve visualization if often difficult from these unilateral approaches, which may affect the ability to achieve a full phrenic to phrenic dissection Herein, we present our early experience of robotic assisted minimally invasive thymectomy (RAMIT) with simultaneous bilateral thoracoscopy and contralateral phrenic nerve visualization.

Methods: This was a retrospective review of all sequential patients undergoing RAMIT with simultaneous bilateral thoracoscopy from January 2015 to May 2016. This study was approved by our Institutional Review Board (PRO15080367). Individual patient consent was waived.

Results: Twenty-six patients [median age 58 (range, 29-76) years] were included in this study. Sixteen operations were performed for anterior mediastinal mass, 7 for non-thymomatous myasthenia gravis, and 3 for concurrent myasthenia gravis and thymoma. Median blood loss and hospital stay were $25 \mathrm{~mL}$ (range, 3-150 mL) and 3 days (range, 2-8 days), respectively. Twenty-one (80.8\%) patients experienced an uncomplicated hospital course. The highest graded complication by Clavien Dindo Classification was a grade III due to pleural effusion requiring drainage via pleural catheter. One patient experienced asymptomatic hemidiaphram palsy postoperatively. There were no 90 -day postoperative deaths.

Conclusions: RAMIT with simultaneous bilateral thoracoscopy is a feasible approach that may allow for enhanced visualization and more complete thymic resection compared to existing unilateral minimally invasive operations. Comparative studies and long-term follow up are needed to adequately assess the potential benefits of RAMIT.

Keywords: Thymectomy; robotic surgery; mediastinum; bilateral thoracoscopy; minimally invasive

Submitted Jul 29, 2019. Accepted for publication Jan 02, 2020.

doi: $10.21037 /$ jtd.2020.01.11

View this article at: http://dx.doi.org/10.21037/jtd.2020.01.11 


\section{Introduction}

Thymectomy is most commonly performed for thymoma and other anterior mediastinal masses, and in cases of medication-refractory myasthenia gravis with or without associated thymoma (1-6). While median sternotomy has been the longstanding approach to thymectomy and anterior mediastinal resections, numerous minimally invasive approaches have emerged in the last several decades (7-9). These minimally invasive approaches appear to reduce operative blood loss, pleural drainage time, and hospitalization times, and have equivalent long-term outcomes to the standard open approaches $(10,11)$. In more recent years, robotic assisted approaches have also been added to the minimally invasive armamentarium (12-24). Potential advantages with this technology include threedimensional view, a high degree of instrument and camera control, and articulated instrumentation.

Regardless of approach, visualization of the phrenic nerves and complete phrenic to phrenic resection remain a central technical principal of the operation. During unilateral thoracoscopic approaches, however, contralateral phrenic nerve visualization is often challenging to clearly achieve. This may limit the ability of the surgeon to safely perform a complete phrenic-to-phrenic thymic resection without significant potential risk of unintended iatrogenic nerve injury. In order to potentially minimize this risk, we incorporated a method of simultaneous and direct imaging of the bilateral phrenic nerves utilizing independent and synchronous video thoracoscopy of the right and left pleural cavities with concurrent visualization of the video images by the surgeon. This study presents our early experience using this technique during robotic-assisted minimally invasive thymectomy (RAMIT).

\section{Methods}

\section{Patients}

This was a retrospective review of all patients undergoing RAMIT with simultaneous bilateral thoracoscopy at the University of Pittsburgh Medical Center from January 2015 to May 2016. All patient information was collected in accordance with the tenets of the Declaration of Helsinki and the Health Insurance Portability Act. This study was approved by the institutional review board at the University of Pittsburgh (PRO15080367).

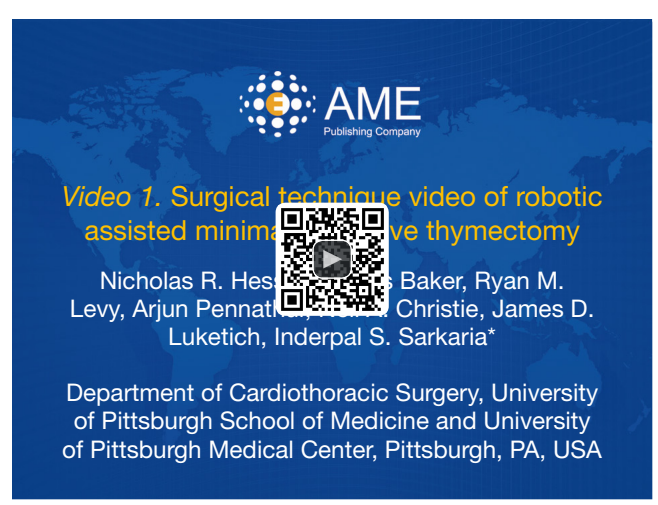

Figure 1 Surgical technique video of robotic assisted minimally invasive thymectomy (25). 0:10, positioning and port placement; $0: 39$, mobilization of left phrenic nerve; $1: 26$, pericardial mobilization; 2:56, division of thymic horns; 5:27, contralateral dissection with bilateral thoracoscopy.

Available online: http://www.asvide.com/watch/33092

\section{Operative technique (Figure 1)}

The authors typically perform RAMIT from a leftsided approach, but may elect for a right-sided approach depending on laterality of the tumor, history of previous operations, or other concurrent pathology. The patient is induced under general anesthesia and a double lumen endotracheal tube is placed. The operation may be performed without lung isolation, although overall exposure may be difficult depending on the individual patient. Insufflation with carbon dioxide to a pressure of $8 \mathrm{mmHg}$ is routinely used to enhance visualization as well. The patient is placed in a semi right lateral decubitus position. The right hemithorax is also exposed and prepped for later contralateral thoracoscopy.

An $8-\mathrm{mm}$ camera port is placed in the $5^{\text {th }}$ intercostal space at approximately the anterior axillary line. Two $8-\mathrm{mm}$ ports are then placed, one in the $5^{\text {th }}$ intercostal space at the mid-clavicular line, and the other in the $3^{\text {rd }}$ intercostal space approximately in the anterior axillary line. A 12-mm assistant port is placed between and caudal to the left hand robotic working port and the camera port, and is also used for removal of the specimen (Figure 2).

In general, the mediastinal pleura anterior to the phrenic nerve is incised and the nerve mobilized away from the operative field, establishing the lateral margin of resection (Figure 3). This dissection plane is carried 


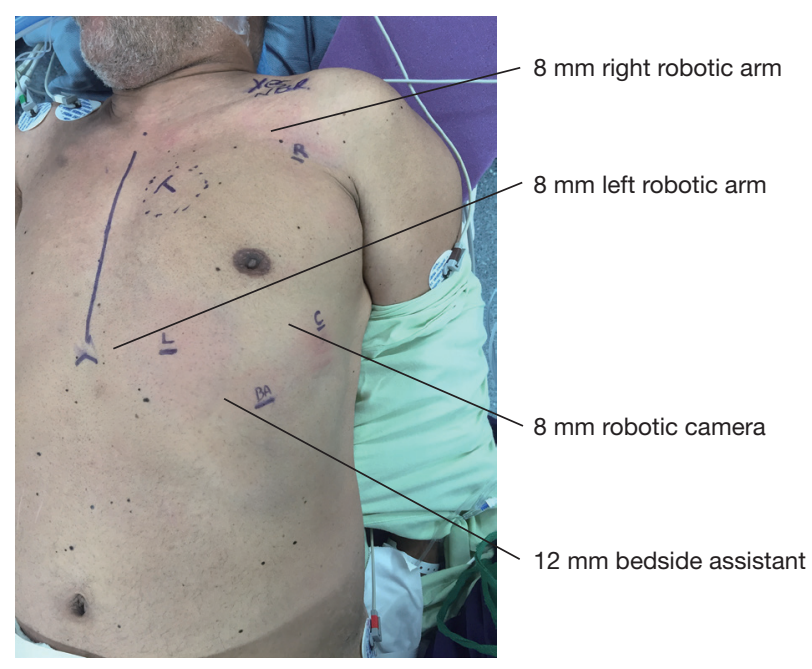

Figure 2 Patient positioning and robotic port placement. Patient is placed in semi right decubitus position. The right chest is also prepped for later installation of contralateral port.

medially, sweeping all thymic tissue and fat en bloc from the pericardium (Figure 4). The pleural incision line is continued along the mediastinal pleura medial to the left internal mammary artery. This dissection plane is continued caudally, as well as medially towards the contralateral internal mammary artery with care to remove all soft tissue and attachments from the posterior sternal table, thus establishing the anterior margin and also removing any potential thymus containing tissue. Dissection is carried to the contralateral pleura, which is opened medial to the contralateral internal mammary artery. Superiorly, the innominate vein is identified and all tissue dissected free and all thymic tributary veins ligated. The left and right thymic horns are distracted caudally with constant, gentle retraction and resected en bloc with the specimen (Figure 5).

In preparation for contralateral (usually right sided) mediastinal dissection and phrenic nerve mobilization, a standard $5-\mathrm{mm}$ port is placed in the right hemithorax in the inframammary fold in the midclavicular line. A thoracoscope is inserted, and video output from this is linked to the robotic imaging console via dedicated software. Thus, both the right and left thoracoscopic images from the standard and robotic scopes are displayed and viewed concurrently on the robotic surgeon's console display, allowing the surgeon to simultaneously visualize both sides of the anterior mediastinum (Figure 6). This technique utilized the pre-existing software that is standard on available robotic operating systems, and does not require

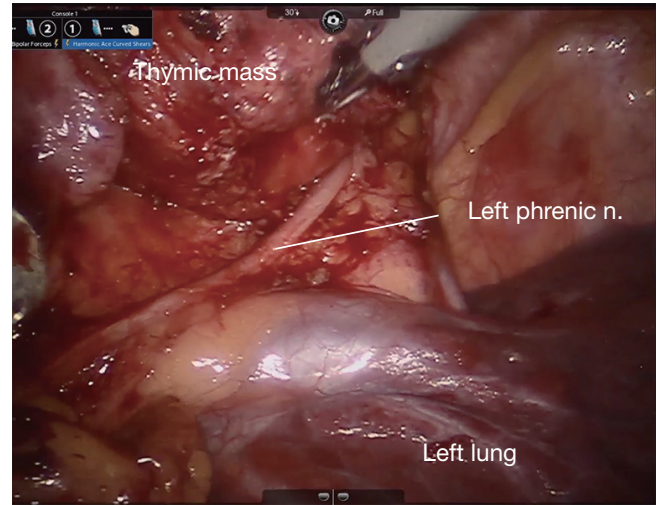

Figure 3 Mobilization of left phrenic nerve. The mediastinal pleura is incised along the length of the phrenic nerve and the nerve is mobilized from the thymus and/or associated thymic mass. n., nerve.

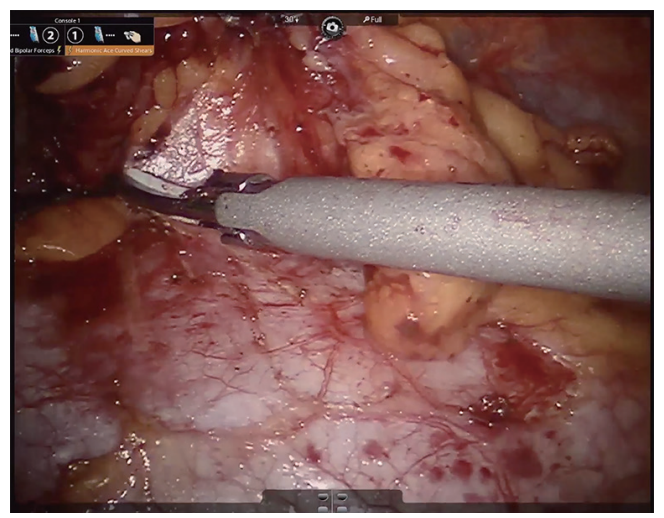

Figure 4 Pericardial dissection. All thymus, pericardial fat, and mediastinal soft tissues are mobilized en bloc from the pericardium.

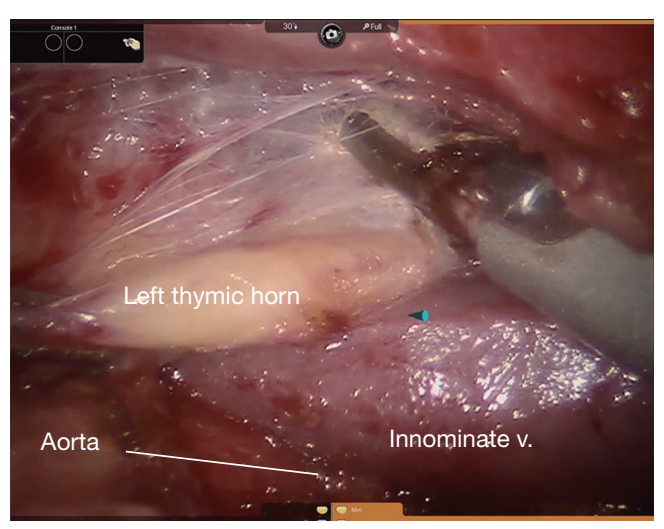

Figure 5 Superior horn division. The left and right superior horns are retracted caudally and divided with the ultrasonic shears. v., vein. 


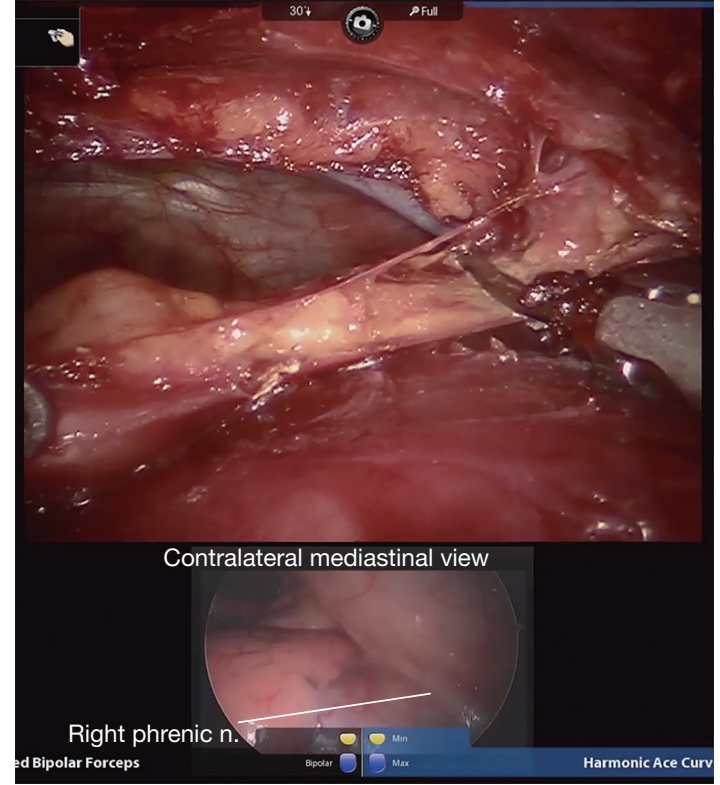

Figure 6 Bilateral thoracoscopy. Video output from contralateral thoracoscope is connected to robotic console, allowing the primary surgeon to maintain simultaneous bilateral visualization of the mediastinum.

downloading of additional software. The bedside assistant controls the contralateral thoracoscope, maintaining synchronous visualization of the right phrenic nerve as the thymectomy is completed via the left sided robotic instruments. Thus, a complete phrenic-to-phrenic en bloc resection is ensured while minimizing risk of contralateral nerve injury.

\section{Results}

\section{Patient demographics}

Twenty-six consecutive patients undergoing RAMIT with simultaneous bilateral thoracoscopy were included in this study. The majority of patients were female (61.5\%) with median age of 58 years (range, 29-76 years). Seven operations $(26.9 \%)$ were performed for non-thymomatous myasthenia gravis, 3 (11.5\%) for myasthenia gravis with thymoma, and 10 (38.5\%) with thymoma only.

\section{Operative characteristics and outcomes}

Twenty-two (84.6\%) patients received RAMIT from a left-sided approach, and 4 (15.4\%) from a right-sided approach. In 4 cases, a second $5 \mathrm{~mm}$ contralateral port was placed for lung retraction and adequate visualization of the contralateral mediastinum and phrenic nerve. Median operative time and estimated blood loss were 188 minutes (range, 140-312 minutes) and $25 \mathrm{~mL}$ (range, 3-150 mL), respectively (Table 1). In most cases, a single transmediastinal chest tube was placed. In one case, a planned en bloc resection of a phrenic nerve was performed due to direct invasion from a thymic squamous cell carcinoma (stage T2N0). In this case, a wedge resection of both the left upper and lower lobes was performed. One patient had a patent left internal mammary to left anterior descending coronary artery bypass graft which was mobilized away from the operative field. There were no conversions to nonrobotic thoracoscopic or open procedures.

\section{Pathological assessment}

Thymoma [10 (38.5\%)] and thymic hyperplasia [6 (23.1\%)] were the two most common histological diagnoses (Table 2). Thymomas were predominantly Masaoka stage IIa [9 (90.0\%)] and WHO histological type AB [6 (60.0\%)]. In two cases, microscopic positive margins were identified on final pathology assessment at the anterior (substernal) margins. In both of these cases, initial frozen section margin evaluation was negative at the time of surgery. Both patients underwent subsequent adjuvant radiotherapy.

\section{Postoperative complications and outcomes}

Median intensive care unit and hospital length of stay were 1 day (range, 0-3 days) and 3 days (range, 2-8 days), respectively (Table 1 ). Twenty-one $(80.8 \%$ ) patients had a postoperative course free from complications. The highest Clavien-Dindo graded complication was a pleural effusion that developed in a patient with previous sternotomy and coronary artery bypass grafting. For this patient, a pigtail catheter was placed and was able to be removed within two days. One patient underwent re-intubation and plasmapheresis for myasthenia gravis. This patient had concurrent myasthenia gravis and thymoma. One patient with MG and concurrent hemangioma, initially thought to be thymoma, required significant and tedious neurolysis to release the phrenic nerve from dense pleural scarring associated with the mass. Although the nerve was clearly intact at the conclusion of the dissection, the patient did develop an asymptomatic ipsilateral hemidiaphragmatic palsy. This palsy was transient, and patient had full 
Table 1 A summary of demographic, intraoperative, and postoperative outcomes and complications following RAMIT with bilateral mediastinal thoracoscopy

\begin{tabular}{|c|c|}
\hline Demographics & Perioperative outcomes \\
\hline Female gender & 16 \\
\hline \multicolumn{2}{|l|}{ Indication for surgery } \\
\hline MG with thymoma & 3 \\
\hline Anterior mediastinal mass & 16 \\
\hline Total operative time, min, median [range] & 188 [140-312] \\
\hline Estimated blood loss, mL, median [range] & $25[3-150]$ \\
\hline Chest tubes, median [range] & $1[1-2]$ \\
\hline Hospital LOS, days, median [range] & $3[2-8]$ \\
\hline \multicolumn{2}{|l|}{ Complications by Clavien Dindo grade } \\
\hline \multicolumn{2}{|l|}{ Grade I } \\
\hline Atrial fibrillation & 1 \\
\hline Supraventricular tachycardia & 1 \\
\hline Urinary retention & 1 \\
\hline Transient hemi-diaphragm palsy & 1 \\
\hline \multicolumn{2}{|l|}{ Grade II } \\
\hline
\end{tabular}

ICU, intensive care unit; LOS, length of stay; MG, myasthenia gravis.

recovery. Median follow up time for patients with either thymoma or thymic carcinoma in this series was 7.3 months (range, 13 days-12.7 months). There was one death at 5.8 months postoperatively due to complications of idiopathic pulmonary fibrosis. There were no cancer recurrences.

\section{Discussion}

In this series, we present the feasibility of simultaneous bilateral thoracoscopy during RAMIT. This technique offers additional and concurrent visualization of the contralateral phrenic nerve and vascular structures while maintaining operative times, blood loss, and ICU and hospital stays comparable to other robotic experiences (Table 3) (12-24,26).

While minimally invasive approaches to thymectomy appear to reduce bleeding, intensive care and hospitalization times when compared to traditional median sternotomy, long-term outcomes data is lacking (11). Currently, it is not well understood whether the quality and completeness of thymic resection is maintained though minimally invasive approaches, especially in the setting of myasthenia gravis where resection of small amounts of residual thymus have demonstrated therapeutic results (27-29). Such findings may be in part why more limited approaches just as the transcervical approach have not been widely adopted.

Thoracoscopic approaches provide excellent visualization to the anterior mediastinum. A unilateral approach, 
Table 2 Histological characterization of resected thymoma and anterior mediastinal masses

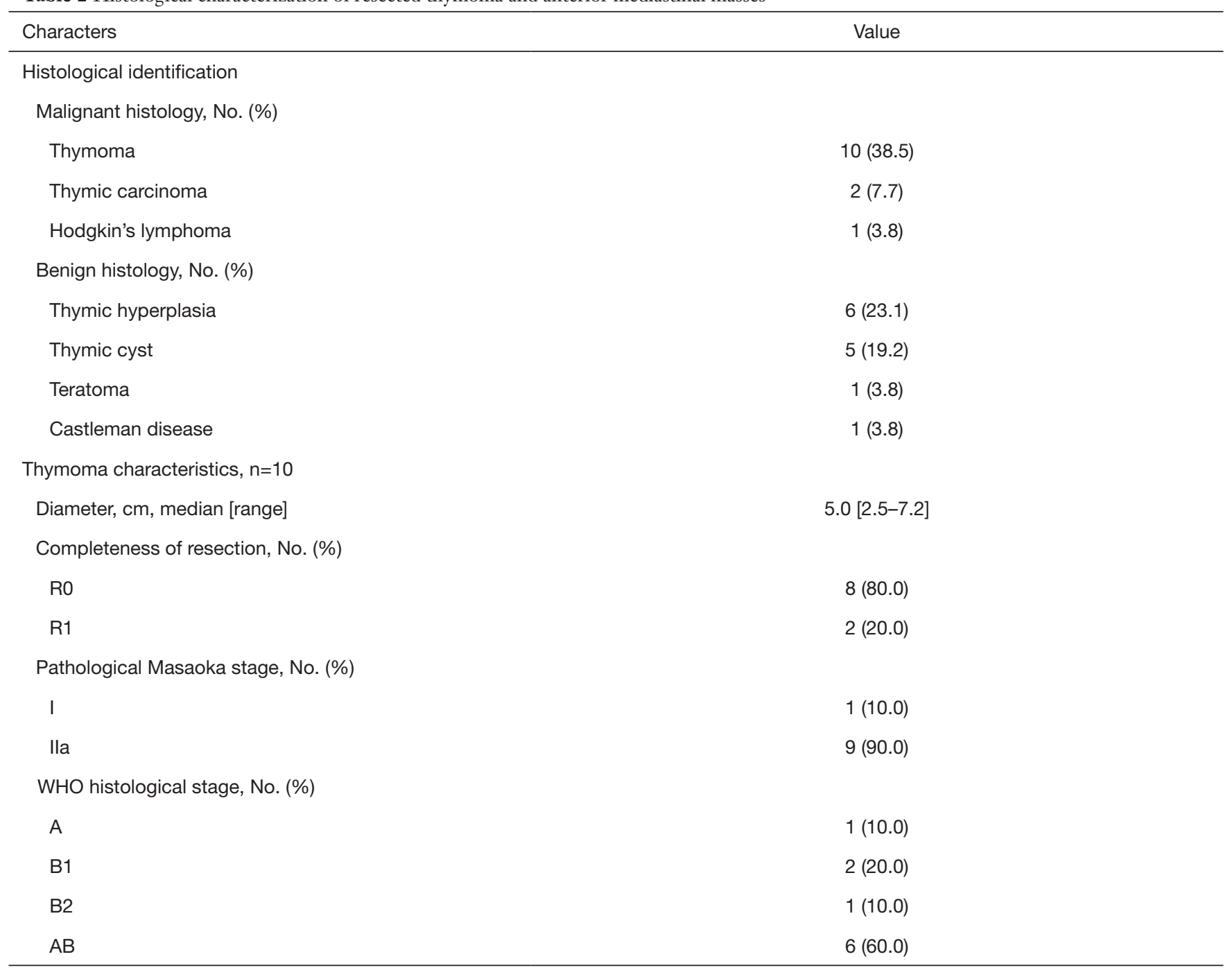

WHO, World Health Organization.

however, does not necessarily provide adequate visualization of the contralateral side nerve and extent of thymic tissue. This may potentially compromise completeness of resection and/or increase the risk of contralateral phrenic nerve or vascular injury. The reported rates of phrenic injury in the existing literature, however, are exceedingly low, with only one robotic series documenting a long-term phrenic injury (Table 3). To restore bilateral mediastinal visualization, bilateral thoracoscopy has been described (30,31). Arguably, these approaches allow the surgeon to improve the extent of thymic resection with greater confidence to avoid injury to the contralateral nerve. A potential limitation of this approach is the ability to provide only unilateral visualization at any given moment. Also, a full complement of working ports is required to work on the contralateral side. Patient repositioning may be also be required. While the impact is likely small compared to the benefit gained, it is not known how such approaches may differentially affect operative time, and post-operative pain and morbidity. Bilateral simultaneous thoracoscopy during RAMIT may be an approach to moderate some of the putative limitations of standard bilateral thoracoscopy. The procedure maintains the high degree of instrument control offered by robotic surgical platforms, allows for efficient and concurrent bilateral mediastinal visualization, and obviates the need for additional contralateral working ports 
Table 3 Literature review of other institutional experience of robotic assisted minimally invasive thymectomy

\begin{tabular}{|c|c|c|c|c|c|c|c|c|c|c|c|}
\hline Author & Year & $\begin{array}{c}\text { Total } \\
\text { patients }\end{array}$ & Indications & Approach & $\begin{array}{l}\text { Operative } \\
\text { time, min }\end{array}$ & $\begin{array}{c}\mathrm{EBL} \\
\mathrm{mL}\end{array}$ & $\begin{array}{l}\text { ICU LOS, } \\
\text { days }\end{array}$ & $\begin{array}{l}\text { Hospital } \\
\text { LOS, days }\end{array}$ & $\begin{array}{c}\text { Conversion } \\
\text { rate }\end{array}$ & Morbidity & $\begin{array}{c}\text { Phrenic } \\
\text { injury }\end{array}$ \\
\hline Keijzers & 2015 & 125 & $\mathrm{MG} \pm$ thymoma & $\mathrm{R}$ & 123 & - & - & 3 & $4 \%$ & $7 \%$ & - \\
\hline Seong & 2014 & 34 & All & $R, L, B / L$ & 157 & 139 & - & 2.7 & $3 \%$ & $0 \%$ & 0 \\
\hline Melfi & 2012 & 39 & All & L & 134 & - & - & - & $4 \%$ & $7 \%$ & 0 \\
\hline Schneiter & 2012 & 68 & All & - & - & - & - & 5 & $0 \%$ & $10 \%$ & 0 \\
\hline Freeman & 2011 & 75 & MG only & L & 113 & - & 0.9 & 2.2 & $1 \%$ & $9 \%$ & 0 \\
\hline Ruckert & 2008 & 106 & $\mathrm{MG} \pm$ thymoma & L & 186 & - & - & - & $1 \%$ & $2 \%$ & $1(0.9 \%)$ \\
\hline Augustin & 2008 & 32 & $\mathrm{MG} \pm$ thymoma & $\mathrm{R}$ & - & - & - & 6 & $3 \%$ & - & 0 \\
\hline
\end{tabular}

R, right; L, left; B/L, bilateral; EBL, estimated blood loss; ICU, intensive care unit; LOS, length of stay; MG, myasthenia gravis.

and patient repositioning. While this technique may not be required for all cases of mediastinal resection, this study has shown its feasibility and may serve as a surgical adjunct for cases where visualization is compromised due to either large degree of mediastinal fat and obstructing soft tissues or difficult patient habitus and/or anatomy. Future studies will be required to identify and elucidate the presence and magnitude of potential benefits.

This study has several limitations. This was a retrospective review of a small single center experience using bilateral thoracoscopy during RAMIT. The patient cohort is heterogeneous in terms of pathology and indication for operation. Also, this study represents a non-controlled case series with no direct comparison to other operative approaches. While the authors have made inferences regarding benefits of this approach, longer-term prospective data and patient follow up is needed to fully evaluate the outcomes of this technique in comparison to other operative approaches.

\section{Conclusions}

RAMIT with simultaneous bilateral thoracoscopy is a feasible approach that may provide a higher degree of safety and allow for a more complete phrenic-to-phrenic thymic resection in comparison to comparable unilateral minimally invasive operations. Comparative studies and long-term follow up are needed to adequately assess the potential benefits of RAMIT.

\section{Acknowledgments}

None.

\section{Footnote}

Conflicts of Interest: Meeting Presentation: Oral presentation at the International Society of Minimally Invasive Cardiothoracic Surgery on June 17, 2016.

Ethical Statement: The authors are accountable for all aspects of the work in ensuring that questions related to the accuracy or integrity of any part of the work are appropriately investigated and resolved. All patient information was collected in accordance with the tenets of the Declaration of Helsinki and the Health Insurance Portability Act. This study was approved by the institutional review board at the University of Pittsburgh (PRO15080367).

\section{References}

1. Davenport E, Malthaner RA. The role of surgery in the management of thymoma: a systematic review. Ann 
Thorac Surg 2008;86:673-84.

2. Falkson CB, Bezjak A, Darling G, et al. The management of thymoma: a systematic review and practice guideline. J Thorac Oncol 2009;4:911-9.

3. Gronseth GS, Barohn RJ. Practice parameter: thymectomy for autoimmune myasthenia gravis (an evidence-based review): report of the Quality Standards Subcommittee of the American Academy of Neurology. Neurology 2000;55:7-15.

4. Jaretzki A, Steinglass KM, Sonett JR. Thymectomy in the management of myasthenia gravis. Semin Neurol 2004;24:49-62.

5. Masaoka A. Extended trans-sternal thymectomy for myasthenia gravis. Chest Surg Clin N Am 2001;11:369-87.

6. Ströbel P, Bauer A, Puppe B, et al. Tumor recurrence and survival in patients treated for thymomas and thymic squamous cell carcinomas: a retrospective analysis. J Clin Oncol 2004;22:1501-9.

7. Bachmann K, Burkhardt D, Schreiter I, et al. Long-term outcome and quality of life after open and thoracoscopic thymectomy for myasthenia gravis: analysis of 131 patients. Surg Endosc 2008;22:2470-7.

8. Meyer DM, Herbert MA, Sobhani NC, et al. Comparative clinical outcomes of thymectomy for myasthenia gravis performed by extended transsternal and minimally invasive approaches. Ann Thorac Surg 2009;87:385-90; discussion 390-1.

9. Keating CP, Kong YX, Tay V, et al. VATS thymectomy for nonthymomatous myasthenia gravis: standardized outcome assessment using the myasthenia gravis foundation of America clinical classification. Innovations (Phila) 2011;6:104-9.

10. Friedant AJ, Handorf EA, Su S, et al. Minimally Invasive versus Open Thymectomy for Thymic Malignancies: Systematic Review and Meta-Analysis. J Thorac Oncol 2016;11:30-8.

11. Hess NR, Sarkaria IS, Pennathur A, et al. Minimally invasive versus open thymectomy: A systematic review of surgical techniques, patient demographics, and perioperative outcomes. Ann Cardiothorac Surg 2016;5:1-9.

12. Keijzers $M$, de Baets $M$, Hochstenbag $M$, et al. Robotic thymectomy in patients with myasthenia gravis: neurological and surgical outcomes. Eur J Cardiothorac Surg 2015;48:40-5.

13. Augustin F, Schmid T, Sieb M, et al. Video-assisted thoracoscopic surgery versus robotic-assisted thoracoscopic surgery thymectomy. Ann Thorac Surg 2008;85:S768-71.
14. Schneiter D, Tomaszek S, Kestenholz P, et al. Minimally invasive resection of thymomas with the da $\operatorname{Vinci}(\mathrm{R})$ Surgical System. Eur J Cardiothorac Surg 2013;43:288-92.

15. Ye B, Tantai JC, Li W, et al. Video-assisted thoracoscopic surgery versus robotic-assisted thoracoscopic surgery in the surgical treatment of Masaoka stage I thymoma. World J Surg Oncol 2013;11:157.

16. Seong YW, Kang CH, Choi JW, et al. Early clinical outcomes of robot-assisted surgery for anterior mediastinal mass: its superiority over a conventional sternotomy approach evaluated by propensity score matching. Eur J Cardiothorac Surg 2014;45:e68-73; discussion e73.

17. Cerfolio RJ, Bryant AS, Minnich DJ. Starting a robotic program in general thoracic surgery: why, how, and lessons learned. Ann Thorac Surg 2011;91:1729-36; discussion 1736-7.

18. Castle SL, Kernstine KH. Robotic-assisted thymectomy. Semin Thorac Cardiovasc Surg 2008;20:326-31.

19. Freeman RK, Ascioti AJ, Van Woerkom JM, et al. Long-term follow-up after robotic thymectomy for nonthymomatous myasthenia gravis. Ann Thorac Surg 2011;92:1018-22; discussion 1022-3.

20. Goldstein SD, Yang SC. Assessment of robotic thymectomy using the Myasthenia Gravis Foundation of America Guidelines. Ann Thorac Surg 2010;89:1080-5; discussion 1085-6.

21. Jun Y, Hao L, Demin L, et al. Da Vinci robot-assisted system for thymectomy: experience of 55 patients in China. Int J Med Robot 2014;10:294-9.

22. Marulli G, Schiavon M, Perissinotto E, et al. Surgical and neurologic outcomes after robotic thymectomy in 100 consecutive patients with myasthenia gravis. J Thorac Cardiovasc Surg 2013;145:730-5.

23. Melfi F, Fanucchi O, Davini F, et al. Ten-year experience of mediastinal robotic surgery in a single referral centre. Eur J Cardiothorac Surg 2012;41:847-51.

24. Rückert JC, Ismail M, Swierzy M, et al. Thoracoscopic thymectomy with the da Vinci robotic system for myasthenia gravis. Ann N Y Acad Sci 2008;1132:329-35.

25. Hess NR, Baker N, Levy RM, et al. Surgical technique video of robotic assisted minimally invasive thymectomy. Asvide 2020;7:052. Available online: http://www.asvide. $\mathrm{com} / \mathrm{watch} / 33092$

26. Ye B, Li W, Ge XX, et al. Surgical treatment of early-stage thymomas: robot-assisted thoracoscopic surgery versus transsternal thymectomy. Surg Endosc 2014;28:122-6.

27. Henze A, Biberfeld P, Christensson B, et al. Failing transcervical thymectomy in myasthenia gravis. An 
evaluation of transsternal re-exploration. Scand J Thorac Cardiovasc Surg 1984;18:235-8.

28. Masaoka A, Monden Y, Seike Y, et al. Reoperation after transcervical thymectomy for myasthenia gravis. Neurology 1982;32:83-5.

29. Jaretzki A 3rd. Thymectomy for myasthenia gravis: analysis of controversies--patient management. Neurologist 2003;9:77-92.

30. Jurado J, Javidfar J, Newmark A, et al. Minimally invasive

Cite this article as: Hess NR, Baker N, Levy RM, Pennathur A, Christie NA, Luketich JD, Sarkaria IS. Robotic assisted minimally invasive thymectomy with simultaneous bilateral thoraco-scopy and contralateral phrenic nerve visualization. J Thorac Dis 2020;12(2):114-122. doi: 10.21037/jtd.2020.01.11 thymectomy and open thymectomy: outcome analysis of 263 patients. Ann Thorac Surg 2012;94:974-81; discussion 981-2.

31. Lee CY, Kim DJ, Lee JG, et al. Bilateral video-assisted thoracoscopic thymectomy has a surgical extent similar to that of transsternal extended thymectomy with more favorable early surgical outcomes for myasthenia gravis patients. Surg Endosc 2011;25:849-54. 